\title{
Association Between Blood Gas Within 1week of Life and Bronchopulmonary Dysplasia in Preterm Infants With Less Than 32 Gestational Weeks
}

\section{Xiaoya Han}

jiangsu province hospital and Nanjing Medical University 1st Affiliated hospital

\section{Xiaolin Miao}

Jiangsu Province Hospital and Nanjing Medical University 1st Affiliated Hospital

\section{Limin Guo}

Jiangsu Province Hospital and Nanjing Medical University 1st Affiliated Hospital

$\mathrm{Na} \mathrm{Li}$

Jiangsu Province Hospital and Nanjing Medical University First Affiliated Hospital

\section{Cun Zhang}

Jiangsu Province Hospital and Nanjing Medical University First Affiliated Hospital

Shudong Cui ( $\nabla$ csd9758@126.com )

Jiangsu Province Hospital and Nanjing Medical University First Affiliated Hospital

\section{Research}

Keywords: bronchopulmonary dysplasia, blood gas, preterm infant, risk factor

Posted Date: December 31st, 2020

DOI: https://doi.org/10.21203/rs.3.rs-136480/v1

License: () (1) This work is licensed under a Creative Commons Attribution 4.0 International License.

Read Full License 


\section{Abstract}

Objective: This study tested wether preterm infants of $₫ 32$ gestational weeks (GWs) with a blood gas derangement within 7days of life are at increased risk for moderate and severe bronchopulmonary dysplasia (BPD).

Method: 236 preterm infants with $₫ 32$ GWs from January of 2017 to December of 2019 were included in this study. First, univariate analysing determined wether there existed associations between BPD (moderate and severe) and blood gas values, clinical characteristics, interventions, daily given liquid and eneregy within 7days of life. Then multivarariate regession analysis was performed to know wether there were relationships between BPD (moderate and severe) and risk factors between which and BPD (moderate and severe) univariate analysing showed that $P$ value was less than 0.1 .

Results: From univariate analysing, we found that $\mathrm{PaO} 2, \mathrm{PaCO} 2$ and $\mathrm{HCO} 3$ in $7^{\text {th }}$ day of life, cesarean section (OR=0.508, 95\% Cl:0.275-0.94), getational age (GA, OR=0.163, 95\%Cl:0.077-0.344), birth weight (BW, OR=0.122, 95\%Cl:0.054-0.273), PDA (OR=2.839, 95\%Cl:1.1463-5.508), early onset infection $(\mathrm{OR}=3.00,95 \% \mathrm{Cl}: 1.483-6.069)$, and mechanical ventilation $(\mathrm{MV}, \mathrm{OR}=4.562,95 \% \mathrm{Cl}: 2.405-8.653)$ were significantly associated with moderate and severe BPD. Because there existed close relationship between $\mathrm{GA}$ and $\mathrm{BW}(\mathrm{R}=0.642, \mathrm{P}=0.000)$ and $\mathrm{BW}$ dispersion was big in this group, we excluded $\mathrm{BW}$ in multivariate analysing. From multivariate analysing, besides $\mathrm{GA}(\operatorname{Exp}(B)=0.176,95 \% \mathrm{Cl}: 0.08-0.389), \mathrm{MV}(\operatorname{Exp}$ $(B)=3.515,95 \% \mathrm{Cl}: 1.746-7.076), \mathrm{PaO} 2(\operatorname{Exp}(B)=0.468,95 \% \mathrm{Cl}: 0.226-0.969)$ in $7^{\text {th }}$ day of life was the independent risk factor for moderate and severe BPD in the preterm infants of $₫ 32 \mathrm{GWs}$.

Conclusion: Preterm infants of $₫ 32 \mathrm{GWs}$ with blood gas derangements within 7days of life could be at risk of moderate and severe BPD.

\section{Background}

Preterm birth is rising around the world, and the incidence of preterm is different ranging from about $5 \%$ in several European countries to $18 \%$ in some African countries[1][2].Bronchopulmonary dysplasia (BPD) is the most common chronic lung disease in preterm infants. BPD is a common cause of death in preterm infants occupying $2.8 \%[3]$. During clinical work, we can not change the fact of preterm delivery. We want to know what we can do to reduce and/or alleviate the development of BPD in the preterm babies, especially in first several days of life. As we know, prolonged exposure to high oxygen concentration is identified as an important contributor to retinopathy of prematurity (ROP)[4]. There exists relationships between severe ROP and blood oxygen, carbon dioxide, and pH levels during the first 3 postnatal days[5] [6]. We deduced that blood gas values $(\mathrm{PH}, \mathrm{PaCO} 2, \mathrm{PaO} 2, \mathrm{HCO} 3)$ in preterm infants be very important for mature of premature organs and systems, and changes of blood gas values in the first several days of life influence the development of premature lung and have an effect on occurence or developent of BPD in preterm infants. If that, we could control blood gas values to reduce and/or alleviate the development of BPD in the preterm babies. It is reported that BPD is associated with exposure to 
antenatal and/or postnatal factors including gestational age, birth weight, gender, patent ductus arteriosus (PDA), mechanical ventilation (MV), oxygen toxicity, and infection[7][8]. In this study, we collected and analyzed such factors as gestational age (GA), birth weight (BW), cesearen section (CS), early onset infection (EOI), anemia, MV (more than 2 days) and blood gas values within 1 week of life ( $1^{\text {st }}$, $2^{\text {nd }}, 3^{\text {rd }}$, and $7^{\text {th }}$ day after birth). We didn't collect data of apgar score due to apgar score in very preterm infants (VPI) and extremly preterm infants (EPI) is lower than that in term babies and low apgar score in VPI and EPI is not equal to neonatal asphyxia, and antenatal corticoid therapy because of antenatal corticoid therapy being as a therapy principle of preterm delivery in the obstetrical department of the first affiliated hospital of Nanjing Medical University.

\section{Materials And Methods}

This retrospective study was conducted at neonatal department of the first affiliated hospital of Nanjing Medical University. Admitting criteria for the study: $₫$ The baby was admitted to the neonatal department from January of 2017 to December of 2019 , $₫$ The preterm infant was $₫ 32$ gestatioal weeks (GWs) , $\nabla$ The preterm baby had no serious congenital anomalies. Exclusion criteria: \lnfants were with congenital anomalies such as congenital lung anomaly, congenital diaphragmatic hernia, severe congenital heart diseases and primary persistent pulmonary hypertension, 区Recorded information was imcomplete, 『An infant was dead and/or refused treatment by parents within 2weeks of life. Excluding of 17cases, we collected 236 cases of preterm infants, who were from $24.9 \mathrm{GWs}$ to $32 \mathrm{GWs}$ (median: 30.4 weeks), whose BW was from $800 \mathrm{~g}$ to $3250 \mathrm{~g}$ (median: $1400 \mathrm{~g}$ ). The study was approved by the ethics review committee of the first affiliated hospital of Nanjing Medical University (2014SR038).

\section{Statistics}

Categorical variables were compared using $\chi 2$ - or Fisher's exact tests. Univariate analysis was used to determine relative risk and $95 \%$ confidence intervals. Logistic regression analysis was used to determine association between BPD and arterial blood gas values on postnatal days 1, 2, 3,and 7 of the preterm infants who were less than 32GWs. All analyses were performed using Stata software version 19.0 (StataCorp LP, College Station, TX, USA). Significance was set at Pख0.05.

\section{Clinical definitions}

BPD was defined as required additional oxygen and/or respiratory support should be equal to or more than continuous 28 days before assessment at 36 weeks of postmenstrual age in preterm infants and classified as mild, moderate and severe based on the required fraction of inspired oxygen at 36 weeks' PMA: mild, no supplemental oxygen; moderate, supplemental oxygen $\leq 30 \%$; and severe, respiratory support and/or oxygen $>30 \%[9]$. Here, oxygen therapy or respiratory support indicated the infant's usual therapy and for oxygen therapy, the treating time was equal to or more than 12 hours of a day in the 
assessing days, not a transient or acute event; target oxygen saturation is 90-95\% [09][10]. GA was established based on last menstrual period confirmed by an ultrasonographic examination prior to 20 weeks [11]. Small for gestaional age (SGA) was defined as infant birth weight less than 10th percentile of BW for the same GA [12]. Early onset infection (EOI) was defined as confirmed infection (including neonatal sepsis, urine tract infection, respiratory infection, etc.) within 7days after birth [13]. Anemia was defined as $\mathrm{Hct}<39 \%[14]$. Patent ductus arteriosus (PDA) was diagnosed by two-dimensional color Doppler examination in $1^{\text {st }}$ week of life.

\section{Results}

\section{Incidence of BPD in the preterm infants}

We collected 253cases with less than 32 weeks of GA in total. After exclusion of 17 cases including incomplete recorded information, dead, refused treatment by parents and severe congenital anomalies, the left 236 preterm infants were included to be analyzed. There existed 54 cases with moderate and severe BPD. The incidence of moderate and severe BPD was $22.88 \%$ in this study.

\section{Clinical characteristics and interventions(see table1)}

\section{Classification}

We choosed the extremely abnormal blood gas values each day $\left(1^{\text {st }}, 2^{\text {nd }}, 3^{\text {rd }}\right.$, and $7^{\text {th }}$ day of life $)$. When the baby's condition was stable, bood gas could just be done one time per day, and the blood gas value was included. We separated each day blood gas values, daily given liquid and energy into a low group and a high group according to each median value(see table2, table3 and table4).

\section{Associations between BPD and clinical characteristics, interventions, each day blood gas values, daily given liquid and eneregy by univariate analysing}

Q From the univariate analysing, we found that such clinical characters as GA, BW, CS, PDA, EOI and MV were significantly associated with BPD. The less GA and lower BW, the more moderate and severe BPD. The preterm infants with PDA, EOI, MV and non CS were at high risk of moderate and severe BPD (see figure1).

\By univariate analysing relationships between moderate and severe BPD and daily given liquid and energy within $1^{\text {st }}$ week of life, the daily given energy in the $7^{\text {th }}$ day of life of preterm infants with BPD was 
lower than that preterm infants with no BPD, no significant difference of daily given liquid in the $1^{\text {st }}$ week of life between preterm infants with BPD and those with no BPD (see figure2 and figure3).

$\triangle$ From the univariate analysing, we found that the blood gas values in the $7^{\text {th }}$ day of life such as PCO2, $\mathrm{PO} 2$ and $\mathrm{HCO} 3$ were significantly associated with BPD. Specifically, higher PCO2, lower PO2 and lower $\mathrm{HCO} 3$ menifasted in preterm infants with BPD in $7^{\text {th }}$ day of life than those in preterm infants with no BPD (see figure4).

\section{Relationships between moderate and severe BPD and risk factors by multivariate analysing}

Although univariate analysing relationship between BW and BPD showed that $P$ value was less than 0.01 , there existed close relationship between $\mathrm{GA}$ and $\mathrm{BW}(\mathrm{R}=0.642, \mathrm{P}=0.000)$ and $\mathrm{BW}$ 's dispersion was big (800-3250g), we excluded BW in multivariate analysing from the first step. From multivariate analysing relationships between BPD and the above risk factors between which and BPD univariate analysing showed that $P$ value was less than $0.1, G A, M V$ and $P O 2$ in $7^{\text {th }}$ day of life were the independent risk factors of BPD in the preterm infants of less than 32GWs (see table5).

\section{Discussion}

The United States National Institutes of Health $(\mathrm{NIH})$ reported an increase of BPD in the past 20 years, more than $40 \%$ preterm infants of 22-28 GWs with BPD[15]. The incidence of BPD in preterm infants of $\triangle$ $32 \mathrm{GWs}$ was reported to be $30 \%$ in the United States[16][17]. The incidence of moderate/severe bronchopulmonary dysplasia was $22 \%$ in less than $1500 \mathrm{~g}$ of birth weight in one study[18]. As to this study, the incidence of morderate and severe BPD was $22.9 \%$ in preterm infants with less than $32 \mathrm{GWs}$. It was similar to the previous study. Infants born at 22-25 GWs have a greater than $50 \%$ risk of BPD, and infants born at 26-27 GWs still have greater than $30 \%$ chance of developing BPD[19]. The incidence of BPD in infants with $B W<1000 \mathrm{~g}, 1000-1249 \mathrm{~g}$ and $1250-1000 \mathrm{~g}$ was $62.3 \%, 25.9 \%$ and $17.3 \%$ respectively[20] .In this research, not only from univariate analyzing but also from multivariate analyzing, we found that BPD was inversely associatd with GA ( $P=0.016, O R=0.342,95 \% \mathrm{Cl}: 0.143-0.819)$, namely, the less $\mathrm{GA} / \mathrm{BW}$ in preterm infants, the higher incidence of BPD.

Mechanical ventilation is an important risk factor for the development of BPD[21] [22]. Because invasive mechanical ventilation could damage premature pulmonary, there is a high morbidity of BPD when preterm infants received long periods of invasive mechanical ventilation[23]. Watterberg reported that reducing mechanical ventilation may improve pulmonary outcomes in ELGAN infants[24]. A metaanalysis compared LISA with mechanical ventilation, LISA had a lower odds of $\mathrm{BPD}(\mathrm{OR}, 0.53 ; 95 \% \mathrm{Cl}$, 0.27-0.96)[25]. It was confirmed by this research that mechanical ventilation is associated with BPD in preterm infants of less than $32 \mathrm{GWs}(\mathrm{OR}, 3.515,95 \% \mathrm{Cl}, 1.746-7.076)$. PDA has also been recognized as a risk factor of BPD[26]. PDA has been linked to the development of BPD[27]. By univariate analyzing, PDA 
was associated with BPD in this group preterm infants(OR=2.839, 95\% Cl: 1.1463-5.508). However, in multivariate regession analyzing, PDA was not associated with BPD. PDA is often present during the period that preterm infants are very susceptible to lung injury leading to BPD. There is overlaping time of PDA existing and lung injury. To day, it remains unclear wether PDA is a true causative risk factor for BPD or just a physiological marker associated with the development of BPD[27].

Neonatal sepsiscould independently increase incidence of BPD[28]. A study reported that increased odds of BPD were found for SGA at $3^{\text {rd }}$ percentile (OR: $\left.3.33,95 \% \mathrm{Cl}: 1.29-8.64\right)$ and neonatal sepsis: coagulasenegative staphylococcal bacteremia (OR: 3.17, 95\% Cl: $2.08-4.83$ ), other bacteremia (aOR: $2.46,95 \% \mathrm{Cl}$ : 1.42- 4.27); and candidemia (aOR: 8.68, 95\% Cl: 1.65- 45.63)[29]. A cohort study including 15839 infants reported $383(2.4 \%)$ cases developed early onset sepsis (EOS) and EOS was associated with increased odds for BPD (OR: 1.74, 95\% Cl: 1.24-2.43)[30]. In this study, we found that EOI was associated with $\mathrm{BPD}$ by univariate analyzing (OR=3.00,95\% Cl: 1.483-6.069), but from multivariate analyzing, $\mathrm{EOI}$ was not the independent risk factor of BPD.

Duan reported that multivarariate logistic regression analysis was performed to determine the association between anemia and BPD[31]. Among 243 preterm infants, the incidence of anemia was higher in BPD patients than that in non-BPD patients $(p<0.001)$. Mean Hct in BPD patients was lower than that in non-BPD patients at different time points ( $1 d, 7 d, 14 d$, and $21 d$ of life). Their results show that early anemia was associated with an increased risk of BPD.We cannot find the relationship between anemia and BPD. It may be caused by that we collected the anemia data within 4weeks of life and did not separate into early anemia (less than 2 weeks of life) and late anemia (more than 2 weeks of life). The association between BPD and anemia and how anemia works on BPD remain to further study. Rocha reported that there existed a significant association between SGA and BPD (OR = 5.2 (Cl: 1.46-18.58), $p=$ 0.01 ) by multivariate analysis[32]. The result was different from ours, we can not find that BPD was associated with SGA. There exist differences between both in the incidence of SGA (up to $18.6 \%$ in this study) and in the study population.

Between days 7 and 27 after birth, every $10 \mathrm{kcal} / \mathrm{kg} / \mathrm{d}$ increase in energy intake was associated with a 9\% reduced risk of BPD $(p=0.029)$ in multivariable models[33]. We found that there existed inversely association between BPD and the $7^{\text {th }}$ day given energy by univariate analysing $(\mathrm{OR}=0.515,95 \% \mathrm{Cl}, 0.275$ 0.962), but there existed no association between both by multivariate analysing. We will continue to collect clinical data to expand the population in order to explicit the relationship between both.

The internal enviroment within $1^{\text {st }}$ week of life such as blood gas values ( PH PCO2 PO2 HCO3) in preterm infants may be very important for the development of premature organs and systems. For infants of less than $32 \mathrm{GWs}$, the infants are during saccular and alveolar stages of lung. If the critical lung development is interrupted by low $\mathrm{PH}$, low $\mathrm{PO} 2$, high $\mathrm{PCO} 2$, and low $\mathrm{HCO}$, there would cause ineffective gas exchange in the preterm lung and the baby would need respiratory support and could suffer from BPD. This study showed that BPD was associated with higher PCO2, lower PO2, and lower $\mathrm{HCO} 3$ in $7^{\text {th }}$ day of life by univariate analyzing, and associated with lower PO2 in $7^{\text {th }}$ day of life through multivariate 
recession analyzing, namely low PO2 in $7^{\text {th }}$ day of life was the independently risk factor of BPD.It suggested that the gas exchang membrane could not recover untill 1 week of life and that continued low $\mathrm{PaO} 2$ till 1 week after birth furth hurt the premature lung and might cause BPD. The specific mechanism of low PaO2 in $7^{\text {th }}$ day of life on BPD need to furth study. As we known, it is first reported that there existed association between blood gas values in the first 7 days of life and BPD.

From the above, low PaO2 in $7^{\text {th }}$ day of life, besides $\mathrm{MV}, \mathrm{GA} / \mathrm{BW}$, was the independent risk factor of moderate and severe BPD in preterm infants of less than $32 \mathrm{GWs}$. Namely, preterm infants of $₫ 32 \mathrm{GWs}$ with blood gas derangements within 7days of life could be at risk of moderate and severe BPD.

\section{Declarations}

\section{Ethics approval:}

The study was approved by the ethics review committee of the first affiliated hospital of Nanjing Medical University (2014SR038)Consent for publication: The manuscript is approved by all authors for publicationAvailability of data and material: The data used or analysed during the study are included in this published article. More detailed data are available from the corresponding author if need.Code availability: N/A

\section{Competing interests:}

we declare no conflicts of interest.

\section{Funding:}

Jiangsu Maternal and Child Health Key Discipline Construction Fund (FXK201730)

\section{Authors' contributions}

Xiaoya Han contributed writing (including drafting), data collection, formal analysis

Xiaolin Miao contributed drafting, data collection (including data curation), data analysis

Limin Guo contributed data collection and curation, methodology

$\mathrm{Na}$ Li contributed data curation

Cun Zhang contributed methodology and data collection.

Shudong Cui contributed design, formal analysis, writing (including review). 


\section{References}

1. Yeo KT. Lee QY, Quek WS, et al; Australian and New Zealand Neonatal Network. Trends in Morbidity and Mortality of Extremely Preterm Multiple Gestation Newborns. Pediatrics 2015 Aug,136(2):263 71. doi: 10.1542/peds.2014-4075. Epub 2015 Jul 13. PMID: 26169427.

2. Blencowe H. Cousens S, Oestergaard MZ, et al. National, regional, and worldwide estimates of preterm birth rates in the year 2010 with time trends since 1990 for selected countries: a systematic analysis and implications. Lancet. 2012 Jun 9;379(9832):2162-72. doi: 10.1016/S01406736(12)60820-4. PMID: 22682464..

3. Jacob J. Kamitsuka M, Clark RH, et al. Etiologies of NICU deaths. Pediatrics. 2015 Jan;135(1):e59-65. doi: 10.1542/peds.2014-2967. Epub 2014 Dec 8. Erratum in: Pediatrics. 2015 Apr;135(4):775-7. PMID: 25489010.

4. PATZ A. HOECK LE, DE LA CRUZ E. Studies on the effect of high oxygen administration in retrolental fibroplasia. I. Nursery observations. Am J Ophthalmol. 1952 Sep;35(9):1248-53. doi: 10.1016/00029394(52)91140-9. PMID: 12976495.

5. Hauspurg AK. Allred EN, Vanderveen DK, et al. Blood gases and retinopathy of prematurity: the ELGAN Study. Neonatology. 2011;99(2):104 - 11. doi: 10.1159/000308454. Epub 2010 Jul 30. PMID: 20689332; PMCID: PMC2939988..

6. Traub T. Said M, Mohamed M. Aly H. Carbon dioxide and retinopathy of prematurity in extremely low birth weight infants. J Matern Fetal Neonatal Med. 2020 Sep;33(17):2882-2888. doi: 10.1080/14767058.2018.1562545. Epub 2019 Jan 3. PMID: 30572751..

7. Jensen EA. Schmidt B. Epidemiology of bronchopulmonary dysplasia. Birth Defects Res A Clin Mol Teratol. 2014 Mar;100(3):145 - 57. doi: 10.1002/bdra.23235. Epub 2014 Mar 17. PMID: 24639412.

8. Trembath A. Laughon MM. Predictors of bronchopulmonary dysplasia. Clin Perinatol. 2012 Sep,39(3):585-601. doi: 10.1016/j.clp.2012.06.014. PMID: 22954271; PMCID: PMC3443959.

9. Jobe AH. Bancalari E. Bronchopulmonary dysplasia. Am J Respir Crit Care Med. 2001 Jun;163(7):1723-9. doi: 10.1164/ajrccm.163.7.2011060. PMID: $11401896 .$.

10. Walsh MC. Wilson-Costello D, Zadell A,et al. Safety, reliability, and validity of a physiologic definition of bronchopulmonary dysplasia. J Perinatol. 2003 Sep,23(6):451-6. doi: 10.1038/sj.jp.7210963. PMID: 13679930.14.Jobe AH.

11. Committee opinion no 611: method for estimating due date. Obstet Gynecol.. 2014 Oct;124(4):863-6. doi: 10.1097/01.AOG.0000454932.15177.be. PMID: 25244460..

12. American College of Obstetricians and Gynecologists. ACOG Practice bulletin no. 134: fetal growth restriction. Obstet Gynecol.. 2013 May;121(5):1122-33. doi: 10.1097/01.AOG.0000429658.85846.f9. PMID: 23635765.

13. Rodwell RL. Leslie AL, Tudehope DI. Early diagnosis of neonatal sepsis using a hematologic scoring system. J Pediatr. 1988 May;112(5):761-7. doi: 10.1016/s0022-3476(88)80699-1. PMID: 3361389.. 
14. Singh R. Visintainer PF, Frantz ID 3rd, et al. Association of necrotizing enterocolitis with anemia and packed red blood cell transfusions in preterm infants. J Perinatol. 2011 Mar,31(3):176 - 82. doi: 10.1038/jp.2010.145. Epub 2011 Jan 27. PMID: 21273983; PMCID: PMC3234132.

15. Stoll BJ. Hansen NI, Bell EF, et al; Eunice Kennedy Shriver National Institute of Child Health and Human Development Neonatal Research Network. Trends in Care Practices, Morbidity, and Mortality of Extremely Preterm Neonates, 1993-2012. JAMA. 2015 Sep 8;314(10):1039-51. doi: 10.1001/jama.2015.10244. PMID: 26348753; PMCID: PMC4787615..

16. Horbar JD. Carpenter JH, Badger GJ, et al Mortality and neonatal morbidity among infants 501 to 1500 grams from 2000 to 2009. Pediatrics. 2012 Jun,129(6):1019-26. doi: 10.1542/peds.2011-3028. Epub 2012 May 21. PMID: 22614775.

17. Isayama T. Lee SK, Mori R, et al; Canadian Neonatal Network; Neonatal Research Network of Japan. Comparison of mortality and morbidity of very low birth weight infants between Canada and Japan. Pediatrics. 2012 Oct;130(4):e957-65. doi: 10.1542/peds.2012-0336. Epub 2012 Sep 10. PMID: 22966031.

18. Brener Dik PH, Niño Gualdron YM, Galletti MF, et al. Bronchopulmonary dysplasia: incidence and risk factors. Arch Argent Pediatr. 2017 Oct 1;115(5):476-482. English, Spanish. doi: 10.5546/aap.2017.eng.413. PMID: 28895695

19. Stoll BJ, Hansen NI, Bell EF, et al. Neonatal outcomes of extremely preterm infants from the NICHD Neonatal Research Network. Pediatrics. 2010;126(3):443-56.

20. Jiangsu Multicenter Study Collaborative Group for Breastmilk Feeding in Neonatal Intensive Care Units. Clinical characteristics and risk factors of very low birth weight and extremely low birth weight infants with bronchopulmonary dysplasia: multicenter retrospective analysis. Zhonghua Er Ke Za Zhi. 2019 Jan 2;57(1):33-39. Chinese. doi: 10.3760/cma.j.issn.0578-1310.2019.01.009. PMID: 30630229.

21. Keszler M. Sant'Anna G. Mechanical Ventilation and Bronchopulmonary Dysplasia. Clin Perinatol. 2015 Dec;42(4):781 - 96. doi: 10.1016/j.clp.2015.08.006. Epub 2015 Oct 1. PMID: 26593078.

22. Klevebro S, Westin V, Stoltz Sjöström E, et al. Early energy and protein intakes and associations with growth, BPD, and ROP in extremely preterm infants. Clin Nutr. 2019 Jun;38(3):1289-1295. doi: 10.1016/j.clnu.2018.05.012. Epub 2018 May 29. PMID: 29885776.

23. Ciuffini F. Robertson CF, Tingay DG. How best to capture the respiratory consequences of prematurity? Eur Respir Rev. 2018 Mar 14;27(147):170108. doi: 10.1183/16000617.0108-2017. PMID: 29540497..

24. Watterberg KL, Gerdes JS, Cole CH, et al. Prophylaxis of early adrenal insufficiency to prevent bronchopulmonary dysplasia: a multicenter trial. Pediatrics. 2004 Dec;114(6):1649-57. doi: 10.1542/peds.2004-1159. PMID: 15574629.

25. Isayama T. Iwami H, McDonald S. Beyene J. Association of Noninvasive Ventilation Strategies With Mortality and Bronchopulmonary Dysplasia Among Preterm Infants: A Systematic Review and Meta- 
analysis. JAMA. 2016 Aug 9;316(6):611 - 24. doi: 10.1001/jama.2016.10708. Erratum in: JAMA. 2016 Sep 13,316(10):1116. PMID: 27532916.

26. Marshall DD, Kotelchuck M, Young TE, et al. Risk factors for chronic lung disease in the surfactant era: a North Carolina population-based study of very low birth weight infants. Pediatrics. 1999;104(6):1345-1350

27. Willis KA. Weems MF. Hemodynamically significant patent ductus arteriosus and the development of bronchopulmonary dysplasia. Congenit Heart Dis. 2019 Jan;14(1):27-32. doi: 10.1111/chd.12691. Epub 2018 Oct 20. PMID: 30343505.

28. Nayeri UA, Buhimschi CS, Zhao G, et al. Components of the antepartum, intrapartum, and postpartum exposome impact on distinct short-term adverse neonatal outcomes of premature infants: $A$ prospective cohort study. PLoS One. 2018 Dec 5;13(12):e0207298. doi: 10.1371/journal.pone.0207298. PMID: 30517142; PMCID: PMC6281222.

29. Lahra MM. Beeby PJ, Jeffery HE. Intrauterine inflammation, neonatal sepsis, and chronic lung disease: a 13-year hospital cohort study. Pediatrics. 2009 May;123(5):1314-9. doi: 10.1542/peds.2008-0656. PMID: 19403497.

30. Klinger G, Levy I, Sirota L, et al; Israel Neonatal Network. Outcome of early-onset sepsis in a national cohort of very low birth weight infants. Pediatrics. 2010 Apr, 125(4): e736-40. doi: 10.1542/peds.20092017. Epub 2010 Mar 15. PMID: 20231184.

31. Duan J, Kong X, Li Q, et al. Association between anemia and bronchopulmonary dysplasia in preterm infants. Sci Rep. 2016 Mar 3;6:22717. doi: 10.1038/srep22717. PMID: 26936610; PMCID: PMC4776173.

32. Rocha G, de Lima FF, Machado AP, et al. The Hypertensive Disorders of Pregnancy Study Group: Small for gestational age very preterm infants present a higher risk of developing bronchopulmonary dysplasia. J Neonatal Perinatal Med. 2019;12(4):419-427. doi: 10.3233/NPM-180129. PMID: 31256077.

33. Abbas S. Keir AK. In preterm infants, does fluid restriction, as opposed to liberal fluid prescription, reduce the risk of important morbidities and mortality? J Paediatr Child Health. 2019 Jul;55(7):860866. doi: 10.1111/jpc.14498. PMID: 31270874..

\section{Tables}


Table 1

Clinical characteristics and interventions of neonates

\begin{tabular}{|c|c|c|}
\hline & classification & number \\
\hline \multirow[t]{2}{*}{ Gender } & male & 134 \\
\hline & femal & 102 \\
\hline \multirow[t]{2}{*}{ CS } & no & 105 \\
\hline & yes & 131 \\
\hline \multirow[t]{2}{*}{ GA } & smedian GA(30.4weeks) & 120 \\
\hline & Imedian GA & 116 \\
\hline \multirow[t]{2}{*}{ BW } & $\leq$ median BW $(1400 \mathrm{~g})$ & 121 \\
\hline & Umedian BW & 115 \\
\hline \multirow[t]{2}{*}{ SGA } & no & 192 \\
\hline & yes & 44 \\
\hline \multirow[t]{2}{*}{ PDA } & $\leq 2 \mathrm{~mm}$ and no PDA & 110 \\
\hline & $\triangle 2 \mathrm{~mm}$ & 126 \\
\hline \multirow[t]{2}{*}{ EOI } & no & 90 \\
\hline & yes & 146 \\
\hline \multirow[t]{2}{*}{ anemia } & no & 89 \\
\hline & yes & 147 \\
\hline \multirow[t]{2}{*}{ RDS } & I stage and no RDS & 127 \\
\hline & II stage and more than II stage of RDS & 109 \\
\hline \multirow[t]{2}{*}{ MV } & no & 160 \\
\hline & yes & 76 \\
\hline
\end{tabular}


Table 2

\begin{tabular}{|llllllll|}
\hline 1st $\mathrm{PH}$ & 1st $\mathrm{PaCO} 2$ & 1st $\mathrm{PaO} 2$ & 1st $\mathrm{HCO}$ & 2nd $\mathrm{PH}$ & 2nd $\mathrm{PaCO} 2$ & 2nd $\mathrm{PaO} 2$ & 2nd $\mathrm{HCO} 3$ \\
\hline 7.30 & 46.25 & 88.5 & 22.3 & 7.39 & 35.45 & 71.00 & 21.30 \\
\hline 3rd $\mathrm{PH}$ & ${ }^{\text {3rd }} \mathrm{PaCO} 2$ & 3rd $\mathrm{PaO} 2$ & ${ }^{3 r d} \mathrm{HCO}$ & ${ }^{7 \text { th }} \mathrm{PH}$ & 7th $\mathrm{PaCO} 2$ & 7th $\mathrm{PaO} 2$ & ${ }^{\text {th }} \mathrm{HCO}$ \\
\hline 7.37 & 37.65 & 67.25 & 21.60 & 7.36 & 39.40 & 71.00 & 22.00 \\
\hline
\end{tabular}

Table 3

\begin{tabular}{|lllllll|}
$\mathbf{1}^{\text {st }}$ fluid & $\mathbf{2}^{\text {nd }}$ fluid & $\mathbf{3}^{\text {rd }}$ fluid & $\mathbf{4}^{\text {th }}$ fluid & $\mathbf{5}^{\text {th }}$ fluid & $\mathbf{6}^{\text {th }}$ fluid & $\mathbf{7}^{\text {th }}$ fluid \\
\hline 71.8 & 84.5 & 96.6 & 105.5 & 115.1 & 123.7 & 131.2 \\
\hline
\end{tabular}

Table 4

\begin{tabular}{|lllllll|}
\hline $\mathbf{1}^{\text {st }}$ energy & $\mathbf{2}^{\text {nd }}$ energy & $\mathbf{3}^{\text {rd }}$ energy & $\mathbf{4}^{\text {th }}$ energy & $\mathbf{5}^{\text {th }}$ energy & $\mathbf{6}^{\text {th }}$ energy & $\mathbf{7}^{\text {th }}$ energy \\
\hline 31.45 & 42.35 & 53.8 & 64.1 & 71 & 78.25 & 83.5 \\
\hline
\end{tabular}

Table 5

Relationship between moderate and severe BPD and risk factors by the multivariate analysing

\begin{tabular}{|llllllll|}
\hline & S.E, & Wals & df & Sig. & $\operatorname{Exp}(B)$ & $95 \% C l$ & \\
\hline GA & 0.404 & 18.476 & 1 & 0.000 & 0.176 & 0.08 & 0.389 \\
\hline PDA & 0.378 & 3.111 & 1 & 0.078 & 1.949 & 0.928 & 4.09 \\
\hline MV & 0.357 & 12.401 & 1 & 0.000 & 3.515 & 1.746 & 7.076 \\
\hline P027 & 0.371 & 4.183 & 1 & 0.041 & 0.468 & 0.226 & 0.969 \\
\hline
\end{tabular}




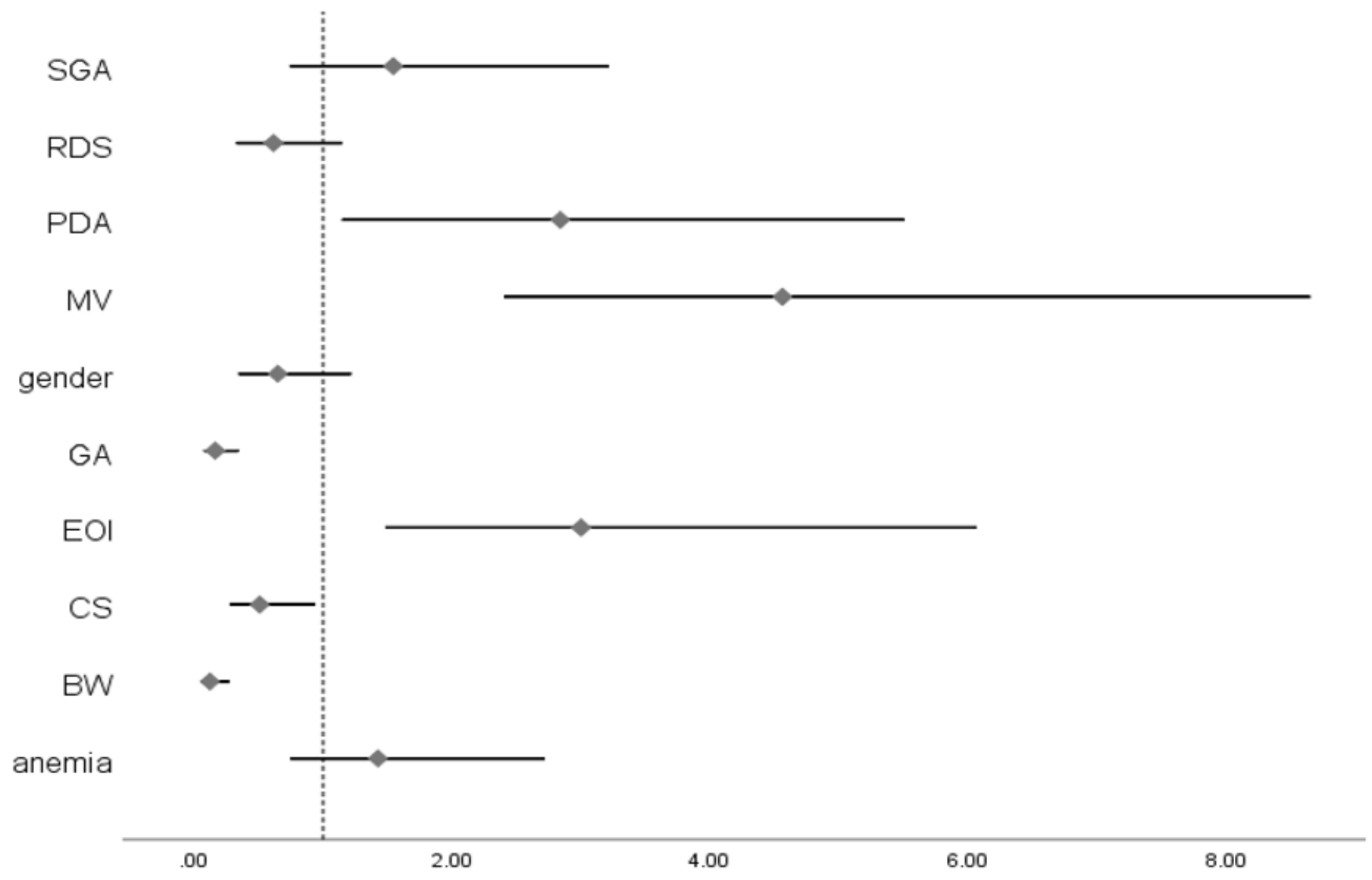

\section{Figure 1}

Relationship between moderate and severe BPD and Clinical characteristics and interventions by univariate analysing 


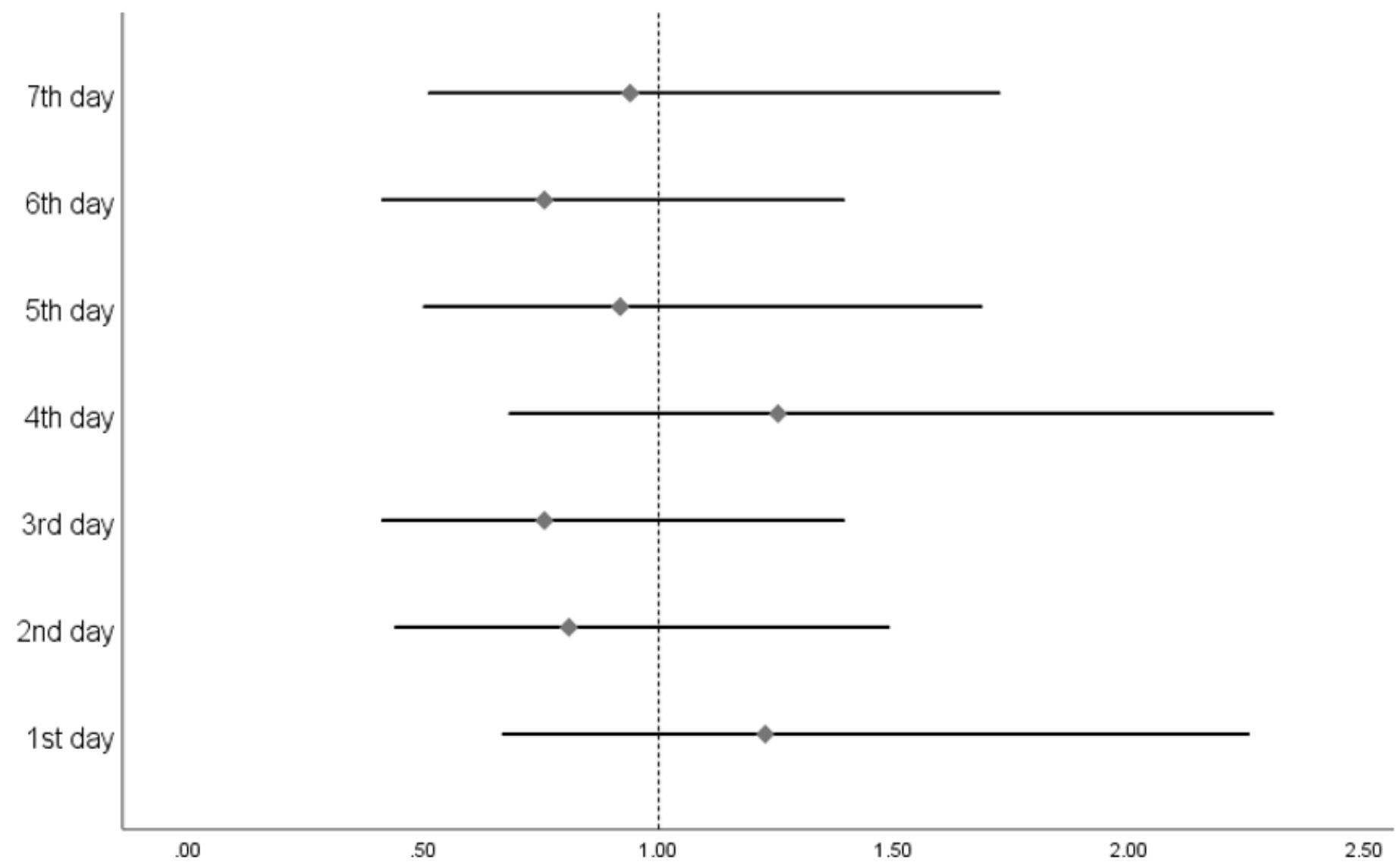

Figure 2

Relationship between BPD and daily given liquid by univariate analysing 


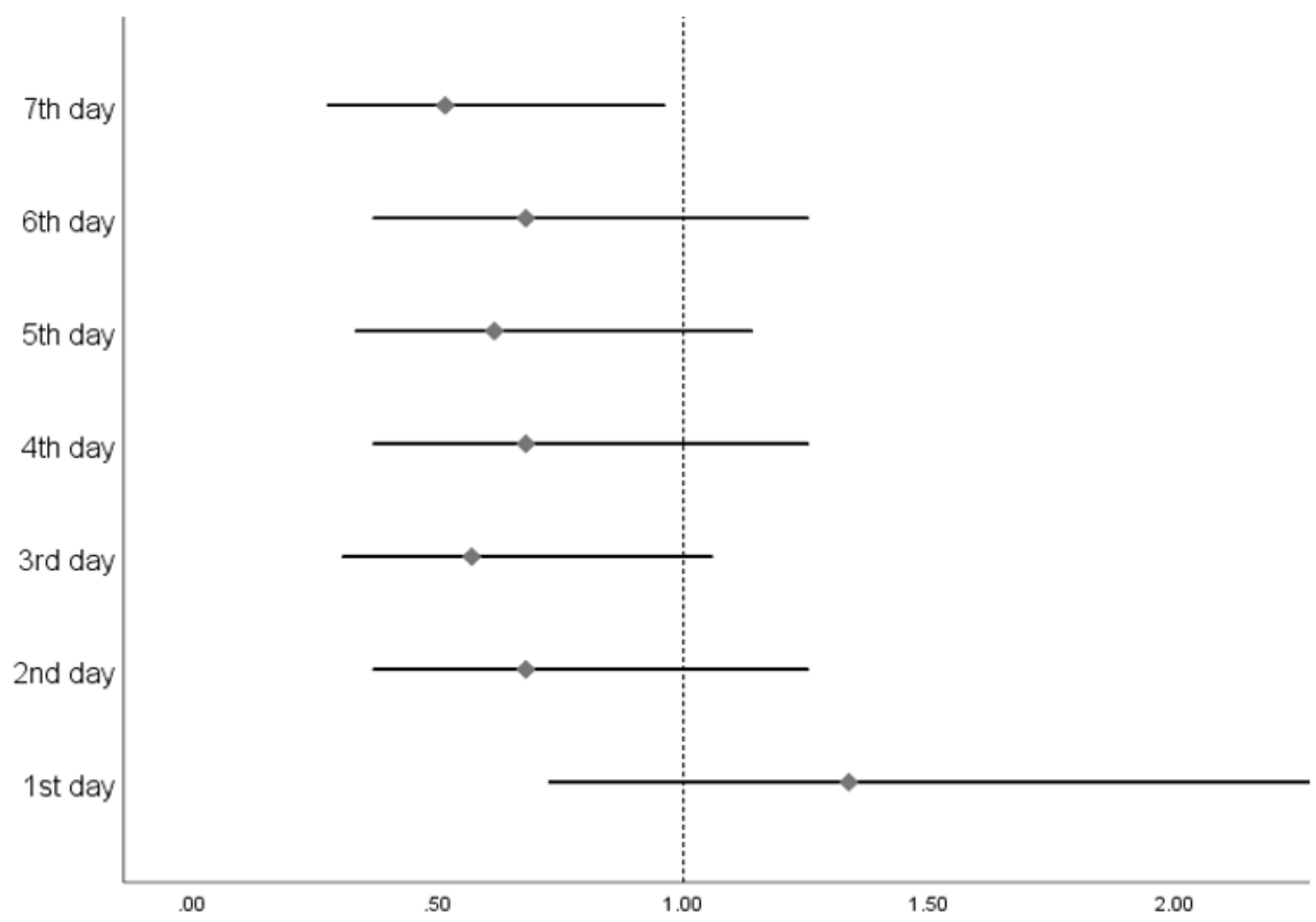

Figure 3

Relationship between moderate and severe BPD and daily given energy by univariate analysing 


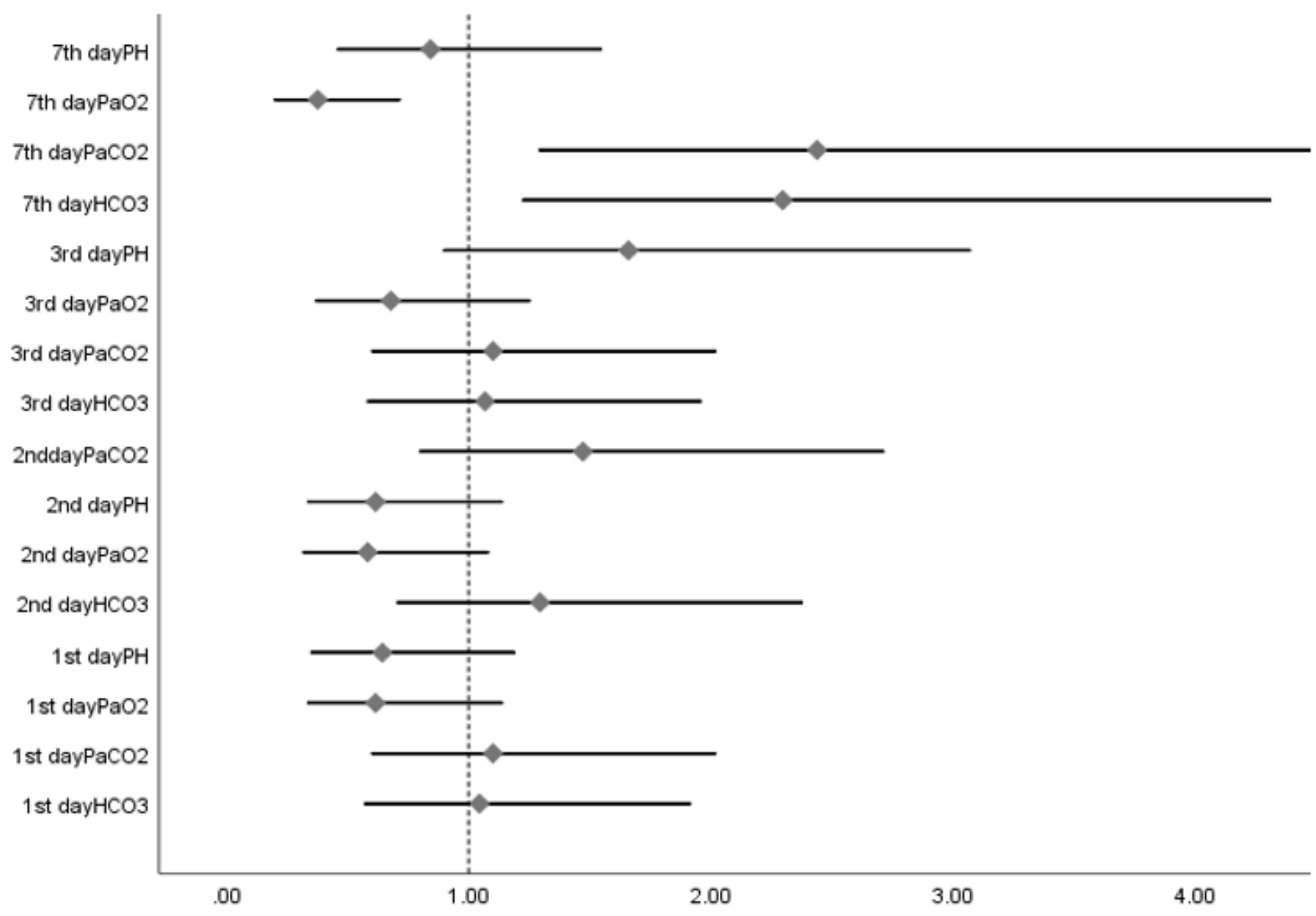

Figure 4

Relationship between moderate and severe BPD and daily blood gas values by univariate analysing 